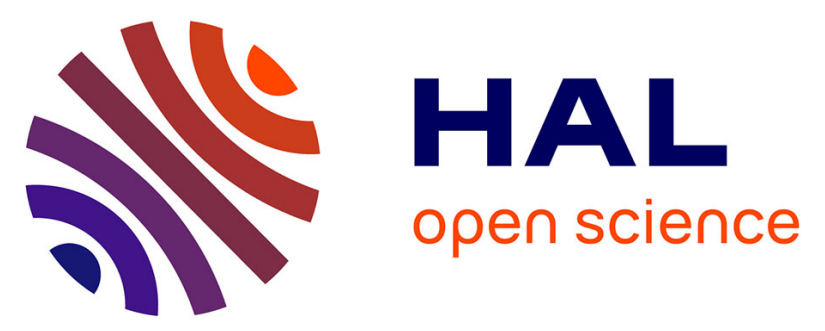

\title{
Differential microstrip patch antenna as feeder of a hyper-hemispherical lens for F-band MIMO radars
}

Dragos Dancila, Václav Valenta, Alina-Cristina Bunea, Dan Neculoiu, Hermann Schumacher, Anders Rydberg

\section{- To cite this version:}

Dragos Dancila, Václav Valenta, Alina-Cristina Bunea, Dan Neculoiu, Hermann Schumacher, et al.. Differential microstrip patch antenna as feeder of a hyper-hemispherical lens for F-band MIMO radars. 2016 Global Symposium on Millimeter Waves (GSMM) \& ESA Workshop on Millimetre-Wave Technology and Applications, Jun 2016, Espoo, Finland. 10.1109/GSMM.2016.7500312 . hal-01361323

\section{HAL Id: hal-01361323 \\ https://hal.science/hal-01361323}

Submitted on 9 Sep 2016

HAL is a multi-disciplinary open access archive for the deposit and dissemination of scientific research documents, whether they are published or not. The documents may come from teaching and research institutions in France or abroad, or from public or private research centers.
L'archive ouverte pluridisciplinaire HAL, est destinée au dépôt et à la diffusion de documents scientifiques de niveau recherche, publiés ou non, émanant des établissements d'enseignement et de recherche français ou étrangers, des laboratoires publics ou privés. 


\title{
Differential Microstrip Patch Antenna as Feeder of a Hyper-Hemispherical Lens for F-Band MIMO Radars
}

\author{
Dragos Dancila ${ }^{1}$, Václav Valenta ${ }^{2}$, Alina-Cristina Bunea ${ }^{3}$, Dan Neculoiu ${ }^{3}$, Hermann Schumacher ${ }^{4}$ and Anders Rydberg ${ }^{1}$ \\ ${ }^{1}$ Uppsala University, Department of Engineering Sciences, Uppsala, Sweden, dragos.dancila@angstrom.uu.se \\ ${ }^{2}$ European Space Agency, The Netherlands \\ ${ }^{3}$ National Institute of R\&D in Microtechnologies (IMT) and Politehnica University of Bucharest, Bucharest, Romania \\ ${ }^{4}$ Ulm University, Institute of Electron Devices and Circuits, Ulm, Germany
}

\begin{abstract}
In this paper, a novel differential microstrip patch antenna (DMPA) is designed and used to feed a lens antenna for short range F-band MIMO radars. The DMPA is fed differentially by a pair of coupled lines. The antenna is connected via a differential impedance matching network to the differential output of the modules, eliminating this way the need of a balun in the RF frontend. The simulated antenna gain is about $8 \mathrm{dBi}$ and bandwidth $\left(\mathrm{S}_{11}<-10 \mathrm{~dB}\right)$ is between $125-137 \mathrm{GHz}$. Preliminary experimental measurements are shown using Transmit/Receive modules in $0.13 \mu \mathrm{m}$ SiGe:C BiCMOS technology, hybrid connected using wirebonding to off chip DMPAs. It is shown by the transmission link evaluation that the gain is increased by about $15 \mathrm{dBi}$ adding a $10 \mathrm{~mm}$ radius 3D printed polyamide lens in the near field of the DMPA.
\end{abstract}

Index Terms - millimeter wave (mm-wave), differential microstrip patch antenna (DMPA), 3D printing, polyamide lens.

\section{INTRODUCTION}

Short-range F-band radar systems based on TransmitReceive (TR) MMIC modules are for instance provided with differential output-inputs. Such modules, implemented in standard SiGe processes using BiCMOS technologies and fast Heterojunction Bipolar Transistors (HBTs) with fmax values of $500 \mathrm{GHz}$ allow the spread of millimeter-wave imaging and radar systems technology [1]. Having the flexibility to operate the TR IC as a transmitter or a receiver is of a great interest for Multiple-Input-Multiple-Output (MIMO) systems and could be implemented on-chip using RF-MEMS [2]. The question of on-chip antenna vs. off-chip hybrid integration is often raised and recent empirical developments have demonstrated the viability of hybrid integration above $100 \mathrm{GHz}$, provided a compensation of bondwire interconnects [3]. At the same time, the hybrid integration allows for instance using large 3D printed lenses for beam focusing. On the other hand, the antenna design should accommodate MMIC's differential interfaces and a traditional solution is the implementation of baluns, while the conventional antennas are of single-ended type. Therefore, research on differential antennas has become more and more attractive recently [4].

In this paper, a novel differential microstrip patch antenna (DMPA) is designed and used to feed a lens antenna for short range F-band MIMO radars. The DMPA is using a differential pair of coupled lines wirebonded to the MMIC and compensation structures. It is shown, by the transmission link evaluation that the gain is increased by about $15 \mathrm{~dB}$ adding a $10 \mathrm{~mm}$ radius $3 \mathrm{D}$ printed polyamide hyper-hemispherical lens in the near field of the DMPA. A manufactured TR module at $130 \mathrm{GHz}$ implementing a differential microstrip patch antenna to feed a hyper-hemispherical lens antenna is shown in Fig. 1

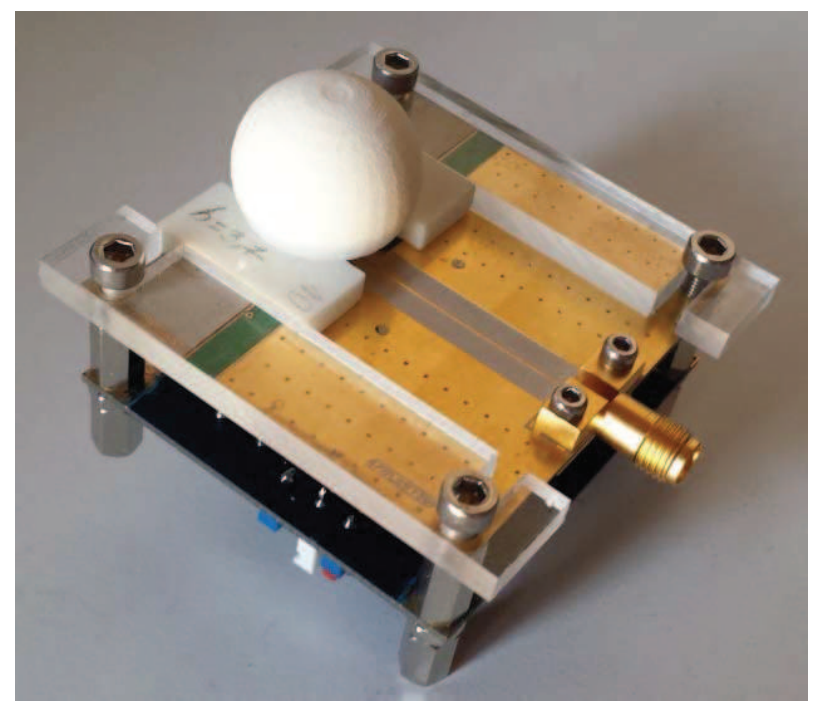

Fig. 1: One of the manufactured TR modules with a hyperhemispherical lens placed above the differential patch.

\section{ANTENNA DESIGN}

A broadside differential patch antenna was designed using the HFSS software. The simulation set-up comprises a port exciting both a differential mode with a characteristic impedance of $100 \mathrm{Ohm}$ and a common mode of $25 \mathrm{Ohm}$, using driven terminal simulations with HFSS. The substrate used is RO3003 with thickness, $h=127 \mu \mathrm{m}$, a relative permittivity $\varepsilon_{r}=3$ and loss tangent, $\tan \delta=0.0013$. Following [5], the initial design starts with the width, $w_{a}$ :

$$
w_{a}=\frac{c}{2 f} \sqrt{\frac{2}{\varepsilon_{r}+1}}
$$

where $c$ is the speed of light and $f$ is the centre frequency. The length, $l_{a}$ can be calculated as:

$$
l_{a}=\frac{\lambda}{2}-2 \Delta l
$$




$$
\frac{\Delta l}{h}=0.412 \frac{\left(\varepsilon_{\text {eff }}+0.3\right)\left(\frac{w_{a}}{h}+0.264\right)}{\left(\varepsilon_{\text {eff }}-0.258\right)\left(\frac{w_{a}}{h}+0.8\right)}
$$

with $\varepsilon_{\text {eff }}$ as the effective permittivity and $\lambda$ as the relative wavelength. A differential feeding with $100 \mathrm{Ohm}$ transmission lines with $l_{l}=700 \mu \mathrm{m}, s_{l}=100 \mu \mathrm{m}$ and $w_{l}=200 \mu \mathrm{m}$ is implemented. A quarter-wavelength matching network is designed as in [6], with $l_{m}=520 \mu \mathrm{m}, w_{m}=100 \mu \mathrm{m}$ and $s_{m}=$ $300 \mu \mathrm{m}$. After optimization, the differential patch antenna dimensions are calculated as follows: $l_{a}=745 \mu \mathrm{m}$ and $w_{a}=$ $545 \mu \mathrm{m}$. The layout of the differential patch antenna designed for a central frequency of $130 \mathrm{GHz}$ is presented Fig. 2.

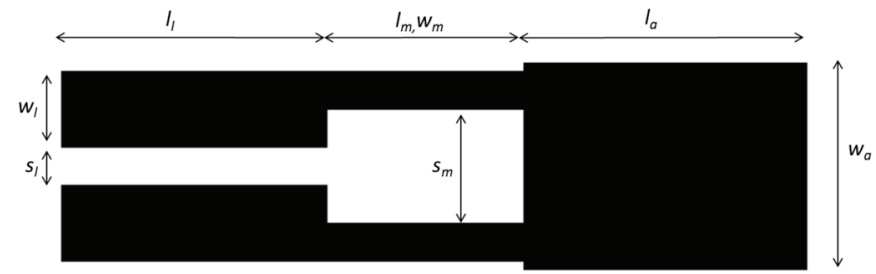

Fig. 2: Layout of the differential patch antenna at $130 \mathrm{GHz}$.

The antenna impedance with and without matching (corresponding to $\mathrm{m} 1$ and $\mathrm{m} 2$ frequency points at $130 \mathrm{GHz}$, respectively) are presented in Fig. 3, for the frequency range 120-140 GHz.

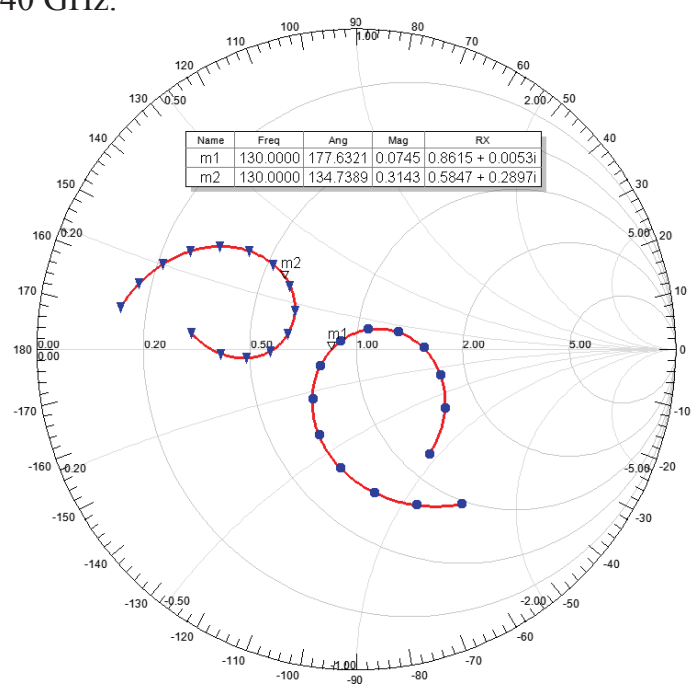

Fig. 3: Antenna impedance with and without matching ( $\mathrm{m} 1$ and $\mathrm{m} 2$ frequency points at $130 \mathrm{GHz}$, respectively) in the frequency range $120-140 \mathrm{GHz}$.

The matching network is designed between the antenna patch and the $100 \mathrm{Ohm}$ differential feed line. The matching network consists of a quarter-wavelength coupled lines and converts the antenna impedance from a slightly inductive part in the Smith chart ( $\mathrm{m} 2$ in Fig. 3) to the $100 \mathrm{Ohm}$ differential impedance ( $\mathrm{m} 1$ in Fig. 3 ).

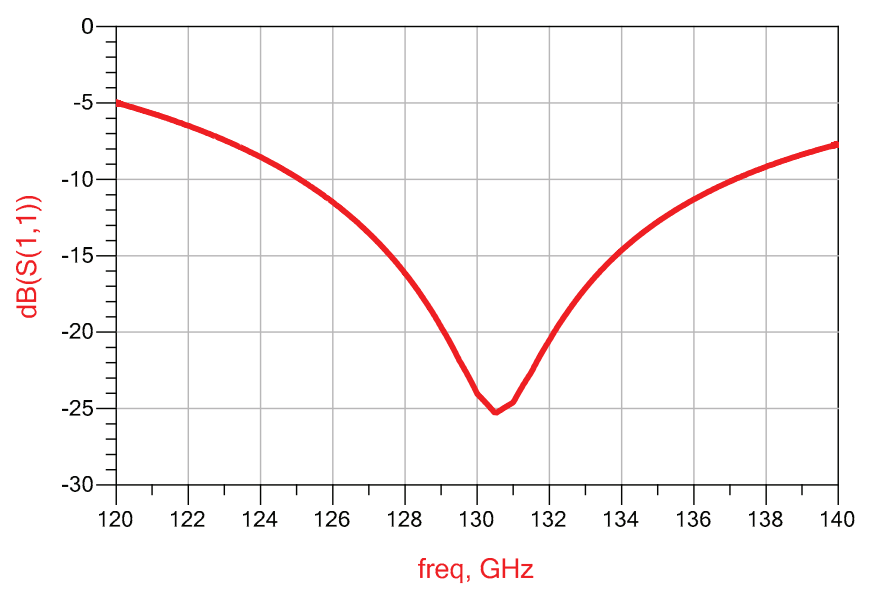

Fig. 4: Design matching $\left(\mathrm{S}_{11}<-10 \mathrm{~dB}\right)$ is between $125-137 \mathrm{GHz}$

The resulting optimised matching is broadband $\left(\mathrm{S}_{11}<-10 \mathrm{~dB}\right)$ between $125-137 \mathrm{GHz}$, see Fig. 4. The radiation pattern is broadside and shows a max gain of $8 \mathrm{dBi}$, as can seen Fig. 5 .
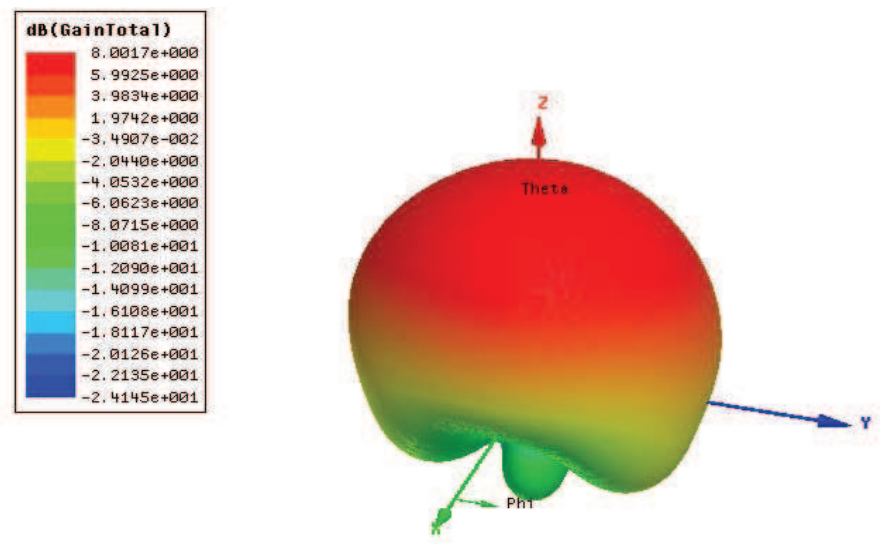

Fig. 5: Far field radiation of the differential patch antenna at $130 \mathrm{GHz}$. The maximum gain is $8 \mathrm{dBi}$.

\section{LENS DESIGN}

The millimeter wave lens was manufactured using a selective laser sintering printing process for $3 \mathrm{D}$ printing of polyamide $\left(\varepsilon_{\mathrm{r}}=3.3\right)$. The lens was integrated in a package and placed at a certain optimized distance $(\mathrm{d}=2.75 \mathrm{~mm})$ above the differential patch antenna. The hyper-hemispherical lens has an extension of $1.5 \times \mathrm{R}$ where $\mathrm{R}=10 \mathrm{~mm}$ is the radius of the lens. The near fields around the differential microstrip patch antenna, feeding the hemispherical lens are presented Fig. 6. 


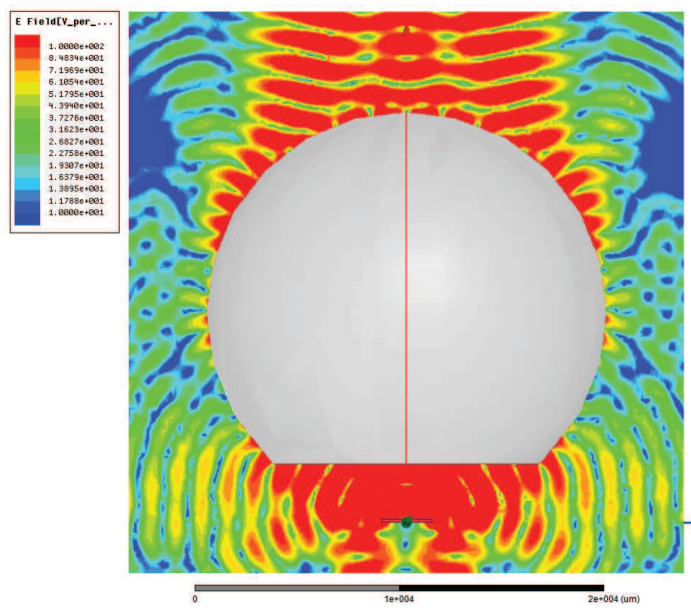

Fig. 6: Fields around the differential microstrip patch antenna, feeding the hemispherical lens (scale: 0 to $\operatorname{Emax}=100 \mathrm{~V} / \mathrm{m}$ ).

In Fig. 7, the directivity of the off-chip antennas is increased by about $13.5 \mathrm{~dB}$ in simulations, using the hyper-hemispherical polyamide lens, with a radius of $10 \mathrm{~mm}$, placed at $2.75 \mathrm{~mm}$ distance from the patch antenna. More details on the design and fabrication of the hemispherical lens could be found in [6].

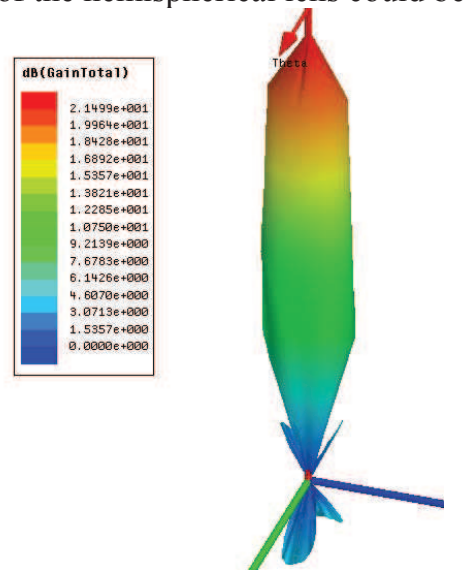

Fig. 7: Far fields of the differential patch antenna with hyperhemispherical lens at $130 \mathrm{GHz}$. The maximum gain is $21.5 \mathrm{dBi}$.

\section{SYSTEM DESCRIPTION}

A block diagram of the TR module is shown in Fig. 8 and a photograph of the fabricated IC is presented in Fig. 9. The TR module can be configured either as a transmitter or a receiver. Therefore, for single-channel radar measurements, two modules are required. Having the flexibility to operate the TR IC as a transmitter or a receiver is of a great interest for Multiple-Input-Multiple-Output (MIMO) systems where different virtual arrays configurations can be arranged [8]. The whole module consists of a TR IC glued into a cavity in a customized board with a differentially fed off-chip end-fire patch antenna, connected to the TR IC using wire bonding. To overcome losses caused by the bondwire interconnects a dedicated compensation structure developed by the authors is used [9]. The TR IC uses frequency multipliers to translate the MIMO radars' specific Frequency-Modulated-ContinuousWave (FMCW) LO signal from X-band to F-Band. The same multiplying topology is used for the down-conversion.

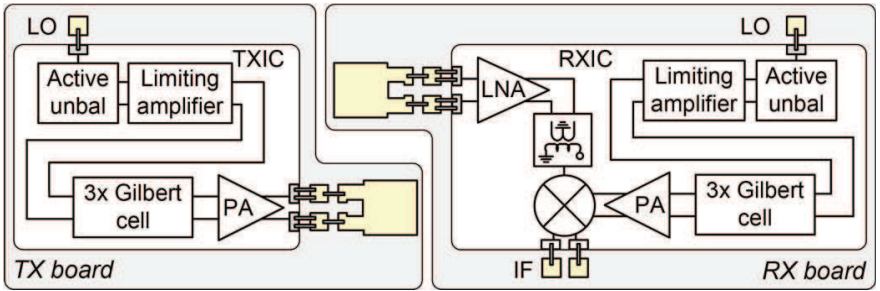

Fig. 8: A block diagram of the Tx and Rx modules used for evaluation of Tx and Rx ICs

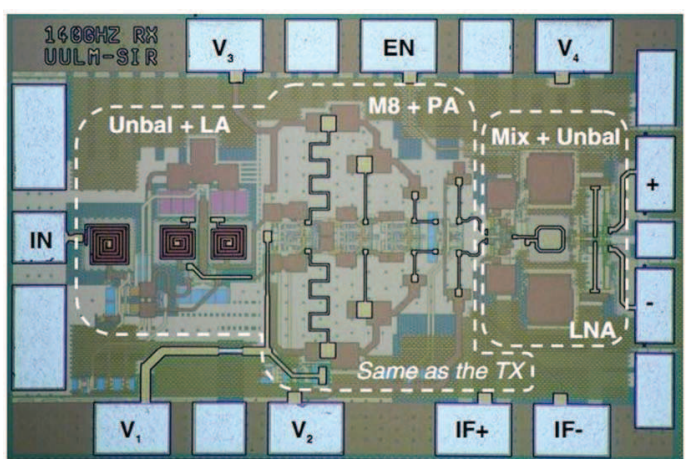

Fig. 9: Chip photograph of the realized Rx IC. The Tx IC is identical with the first section of the Rx (highlighted by the dashed line). The $\mathrm{Rx}$ occupies an area of $0.52 \mathrm{~mm}^{2}$.

\section{EXPERIMENTAL RESULTS}

Two TR ICs were hybrid connected using wirebonding to the differential antenna: ICs realized in SG13S technology $\left(\mathrm{f}_{t} / \mathrm{f}_{\max }=250 / 300 \mathrm{GHz}\right)$ were packaged into customized boards made of three separate PCBs. The bottom PCB is FR4 and contains all bonding pads and routing for DC, IF, digital control and ESD protection. The second board is a $130 \mu \mathrm{m}$ thick RO3003 with $9 \mu \mathrm{m} \mathrm{Cu}$ cladding, suitable for fabrication of fine off-chip structures (antenna and bondwire compensation). The input LO feed is made on a separate RO3003. Fig. 10 shows a cross-section and a photograph of the realized module.

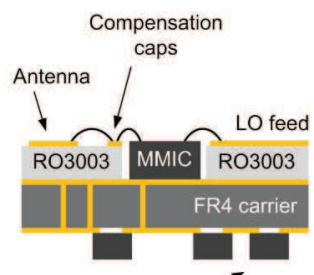

$\mathrm{DC}$, IF routing, ESD

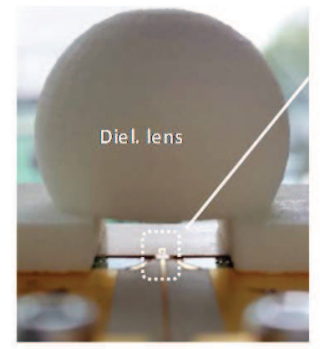

Fig. 10: A cross-section and a photograph of the realized TR IC module. Differential end-fire antenna, bondwire interconnect compensation elements and the LO feed line on RO3003. 
In the experiment, two TR modules were arranged in a bidirectional $0.5 \mathrm{~m}$ wireless link. Two independent LO signals with offset of $1 \mathrm{MHz}$ were swept from 13.75 to $17.5 \mathrm{GHz}$ (i.e. 110 to $140 \mathrm{GHz}$ at the wireless interface) and fed to the modules to create an IF tone exactly at $8 \mathrm{MHz}$. While sweeping the LOs, the resulting $8 \mathrm{MHz}$ IF was recorded at the mixer's output (before the off-chip op-amps). Frequency responses for SG13S TR modules are shown in Fig. 11.

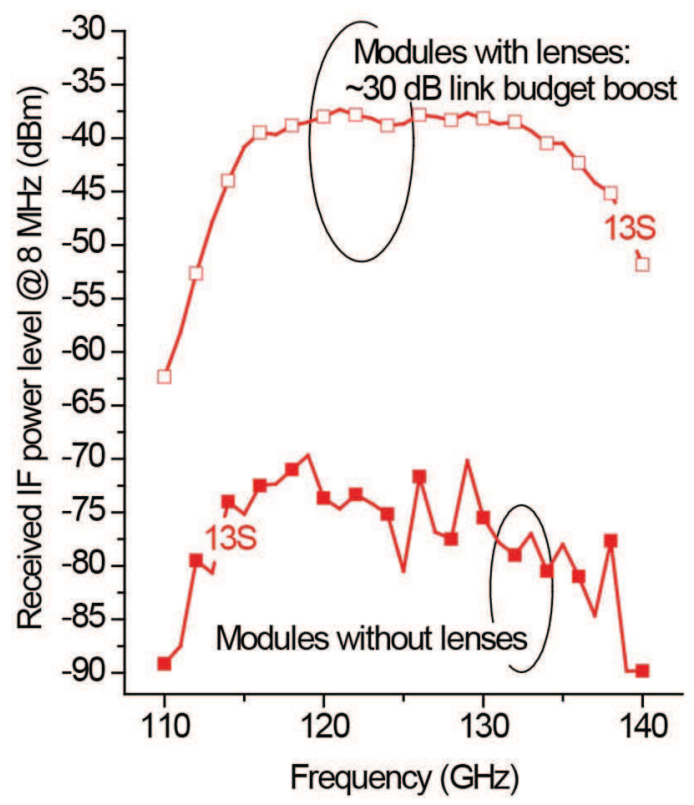

Fig. 11: Frequency responses for a $0.5 \mathrm{~m}$ wireless link (left). Note the wide bandwidth $(>20 \mathrm{GHz})$ of the wire-bonded $13 \mathrm{~S}$ modules.

\section{CONCLUSIONS}

A differential microstrip patch antenna was wirebond connected to SiGe BiCMOS TR modules, demonstrating a $0.5 \mathrm{~m}$ wireless link between 120-140 GHz. By simulations, a gain increase of about $13.5 \mathrm{~dB}$ is obtained using a hyperhemispherical lens with a radius of $10 \mathrm{~mm}$ and placed optimally above the patch antenna. Experimental results using two TR modules show that the gain is increased by about $15 \mathrm{~dB}$, adding a $10 \mathrm{~mm}$ radius $3 \mathrm{D}$ printed polyamide lens above the differential patch antenna. The overall link budget is therefore improved by about $30 \mathrm{~dB}$, demonstrating the very high directivity of this solution.

\section{ACKNOWLEDGEMENTS}

This work is supported by the EU project NANOTEC (FP7ICT-2011-7). The authors wish to acknowledge Dr. M. Kaynak from IHP GmbH and Dr. W. Winkler from Silicon Radar GmbH.

A.C. Bunea and D. Neculoiu would like to thank Mr. Victor Moagar-Poladian and Dr. Gabriel Moagar-Poladian for manufacturing the 3D printed lens, for useful discussions regarding the $3 \mathrm{D}$ printing process and acknowledge the support of the Romanian Ministry of National Education and Research, under the project no. PN-IIID-PCE-2011-3-0830.

\section{REFERENCES}

[1] H. Schumacher, M. Kaynak, V. Valenta, B. Tillack, "Smarter ICs," Microwave Magazine, IEEE , vol.13, no.7, pp.S33,S40, Nov.-Dec. 2012.

[2] T. Spreng, S. Yuan, V. Valenta, H. Schumacher, U. Siart and V. Ziegler, "Wideband $120 \mathrm{GHz}$ to $140 \mathrm{GHz}$ MIMO radar: System design and imaging results," Microwave Conference (EuMC), 2015 European, Paris, 2015, pp. 430-433

[3] V. Valenta T. Spreng V. Ziegler D. Dancila A. Rydberg and H. Schumacher, "Design and Experimental Evaluation of Compensated Bondwire Interconnects above $100 \mathrm{GHz}$," International Journal of Microwave and Wireless Technologies, 2014.

[4] Y. P. Zhang, J. J. Wang, "Theory and analysis of differentially-driven microstrip antennas," IEEE Trans. On Antennas and Propagation, vol. 54, No. 4, 2006.

[5] Constantine A. Balanis, Antenna Theory: Analysis and Design, 2nd edition, John Wiley \& Sons. Inc., USA, pp.727-730, 1997.

[6] Z. Tong, C. Wagner, R. Feger, A. Stelzer and E. Kolmhofer, "A Novel Differential Microstrip Patch Antenna and Array at 79 GHz,” Int. Symp. on Antennas and Propagation, pages 1-5, Taipei, TW, Oct. 2008.

[7] A. C. Bunea, D. Neculoiu, A. Avram and C. Rusch, "Investigation of a Membrane Supported D-Band Antenna with a 3D Printed Polyamide Lens", in Asia-Pacific Microwave Conference (APMC), 2014 IEEE, Nov. 2014 pp. 471-473.

[8] V. Valenta, W. Winkler, T. Spreng, M. Kaynak, D. Dancila, A. Rydberg, S. Yuan, A. Trasser and H. Schumacher, High Performance Transmit/Receive Modules in $0.13 \mu \mathrm{m}$ SiGe:C BiCMOS for Short Range F-band MIMO Radars, IMS'14, Tampa Bay, Florida, USA, 1-6 June 2014.

[9] V. Valenta, D. Dancila, T. Spreng, V. Ziegler, A. Rydberg and H. Schumacher, Experimental Evaluation of Differential Chip-to-Antenna Bondwire Interconnects above $100 \mathrm{GHz}$, EUMW'14, Rome, Italy, 5-10 October 2014. 